\title{
A rare mutation of thyroid hormone receptor beta gene in thyroid hormone resistance syndrome
}

\author{
Michela Del Prete ${ }^{1} 1$, Fabrizio Muratori1, Irene Campi², Gianleone Di Sacco1, \\ Federico Vignati', Domenico Pellegrino ${ }^{3}$ and Luca Persani $(10,4$
}

1Division of Endocrinology and Diabetology, Sant'Anna Hospital - ASST Lariana, Como, Italy, 2Department of Endocrine and Metabolic Diseases, Lab of Endocrine and Metabolic Research, San Luca Hospital, IRCCS Istituto Auxologico Italiano, Milan, Italy, ${ }^{3}$ Division of Geriatrics, Sant'Anna Hospital - ASST Lariana, Como, Italy, and ${ }^{4}$ Department of Medical Biotechnologies and Translational Medicine, University of Milan, Milan, Italy
Correspondence should be addressed to M Del Prete

Email

michela.delprete@ asst-lariana.it

\section{Summary}

Resistance to thyroid hormone (RTH) is a rare hereditary syndrome with impaired sensitivity to thyroid hormones (TH) and reduced intracellular action of triiodothyronine (T3) caused by genetic variants of TH receptor beta (TRB) or alpha (TRA). RTH type beta (RTH $\beta$ ) due to dominant negative variants in the TRB gene usually occurs with persistent elevation of circulating free $\mathrm{TH}$, non-suppressed serum TSH levels responding to a thyrotropin-releasing hormone (TRH) test, an absence of typical symptoms of hyperthyroidism and goiter. Here, we present a rare variant in the TRB gene reported for the first time in an Italian patient with generalized RTH $\beta$ syndrome. The patient showed elevated TH, with non-suppressed TSH levels and underwent thyroid surgery two different times for multinodular goiter. The genetic test showed a heterozygous mutation in exon 9 of the TRB gene resulting in the replacement of threonine (ACG) with methionine (ATG) at codon 310 (p.M310T). RTH $\beta$ syndrome should be considered in patients with elevated TH, non-suppressed TSH levels and goiter.

\section{Learning points:}

- Resistance to thyroid hormone (RTH) is a rare autosomal dominant hereditary syndrome with impaired tissue responsiveness to thyroid hormones $(\mathrm{TH})$.

- Diagnosis of RTH is usually based on the clinical finding of discrepant thyroid function tests and confirmed by a genetic test.

- RTH is a rare condition that must be considered for the management of patients with goiter, elevation of TH and non-suppressed serum TSH levels in order to avoid unnecessary treatments.

\section{Background}

Resistance to thyroid hormone (RTH), also known as Refetoff syndrome (1), is a rare autosomal dominant hereditary syndrome with impaired tissue responsiveness to thyroid hormones (TH) (2). RTH syndrome includes not only mutations in the TH receptor (TR) beta (TRB) or alpha (TRA) genes but also defects in TH transport and metabolism (2). Most of the RTH cases are due to heterozygous mutations of the TRB gene (3). Limited 
studies found the occurrence of one case per 40000 live births and, to date, more than 3000 cases have been published (4).

Patients with RTH syndrome may have variations in resistance severity to $\mathrm{TH}$ according to the different expression levels of TRB and, consequently, in clinical presentation. The most common features of RTH $\beta$ syndrome are persistent elevation of circulating free $\mathrm{TH}$, non-suppressed serum TSH levels responding to thyrotropin-releasing hormone (TRH) test, an absence of typical symptoms of hyperthyroidism and goiter.

Here, we present a case of a patient with $\mathrm{RTH} \beta$ with a rare mutation of the TRB gene.

\section{Case presentation}

A 60-year-old female patient was referred to our endocrinology service for evaluation of thyroid dysfunction. The medical history of the patient started in 1972 when she was diagnosed with diffuse goiter and thyroid hyperfunction with radioiodine uptake of $52 \%$ at $3 \mathrm{~h}$ and $87 \%$ at $24 \mathrm{~h}$. At that time, the patient did not show signs or symptoms of hyperthyroidism and, according to her laboratory tests, she was treated with antithyroid medications. She did not report further clinical measurements from 1972 to 1986.

In 1986, laboratory tests showed high levels of free T4: $42.00 \mathrm{pmol} / \mathrm{L}$ (normal range (NR): 9.00-25.00), free T3: $3.12 \mathrm{pg} / \mathrm{mL}$ (NR: 0.90-2.00) and non-suppressed levels of TSH: $1.50 \mu \mathrm{U} / \mathrm{mL}$ (NR: 0.1-4.3). Anti-thyroglobulin and anti-microsomal thyroid antibodies were negative. Although this finding of discrepant thyroid function tests, no further investigations were performed. She underwent subtotal thyroidectomy with a histological diagnosis of diffuse goiter. After the surgery, due to the recurrence of nodular goiter, in 1992 she started therapy with levothyroxine (L-T4) $50 \mu \mathrm{g} /$ day increased to $100 \mu \mathrm{g} /$ day, without achieving an effective suppression of TSH (3.12 $\mu \mathrm{U} / \mathrm{mL}$ ).

During the subsequent follow-ups, the thyroid ultrasonography showed an increase in diameter of several confluent nodules in the right $(7 \times 9 \mathrm{~cm})$ and the left $(7 \times 8 \mathrm{~cm})$ remnant thyroid tissue. A thoracic $\mathrm{X}$-Ray examination revealed right tracheal deviation. In March 2004, she underwent a second surgery with total thyroidectomy. The histological examination confirmed the diagnosis of a multinodular goiter.

Post-surgery ultrasonography examination showed remnant thyroid tissue in both lobes. On L-T4 replacement $(1.7 \mu \mathrm{g} / \mathrm{kg} /$ day), laboratory tests confirmed high levels of free T4: $2.86 \mathrm{ng} / \mathrm{dL}$ (NR: 0.78-2.19) and free T3: $7.03 \mathrm{pg} /$ $\mathrm{mL}$ (NR: 2.77-5.27) and non-suppressed levels of TSH: $2.87 \mu \mathrm{U} / \mathrm{mL}$ (NR: 0.46-4.68).

In 2018, the patient also underwent outer quadrantectomy for a grade 2 ductal carcinoma (9 $\mathrm{mm}$ ) of the right breast positive for estrogen and progesterone receptors. After the surgery, she received a hypofractionated radiotherapy schedule of 45 Gy in 20 fractions and hormonotherapy.

\section{Investigation}

In December 2019, when the patient was seen for the first time in our service, a genetic test was required to confirm the diagnosis of RTH syndrome. Thus, DNA was isolated from the peripheral blood cells of the patient. Molecular analysis was performed with targeted next generation sequencing (NGS) technique which includes a panel of genes involved in thyroid hormone actions using Illumina Nextera Rapid Capture Custom Enrichment kits (Illumina, San Diego, CA). The PCR amplification was performed on coding regions and intron/exon junctions of the TRA, TRB, DIO1, SLC16A2 and SECISBP2 genes. Sanger sequencing confirmed the presence of a heterozygous mutation in exon 9 of the TRB gene (c.929T>C) resulting in the replacement of threonine (ACG) with methionine (ATG) at codon 310 (p.M310T) (Fig. 1).

The patient had no dyslipidemia or other laboratory alterations and performed echocardiography showing normal cardiac parameters. Her TH profile showed free T4: $2.56 \mathrm{ng} / \mathrm{dL}$ (NR: 0.78-2.19), free T3: $6.20 \mathrm{pg} / \mathrm{mL}$

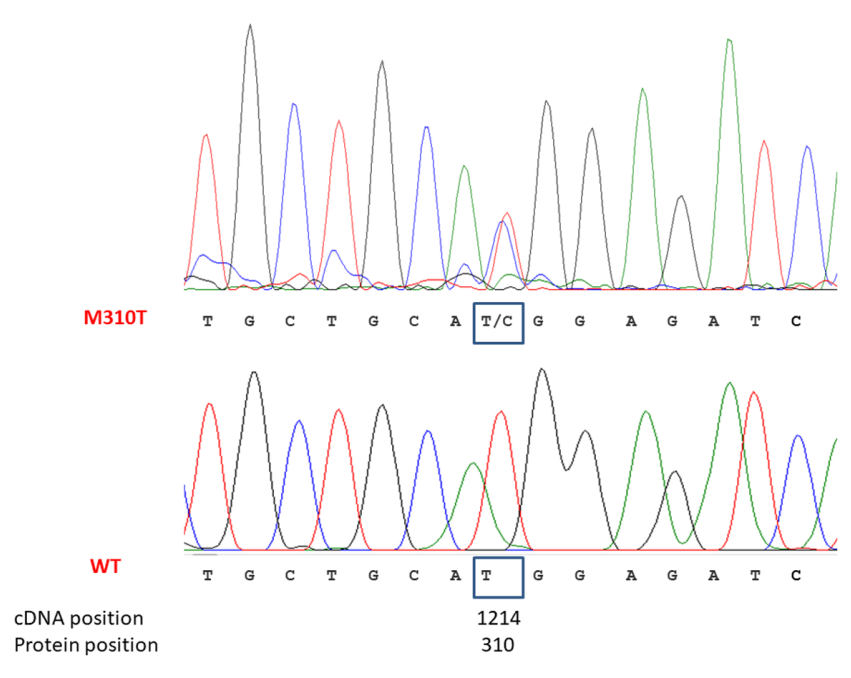

Figure 1

DNA sequence analysis of the TRB gene showing a heterozygous mutation located in exon 9. 
(NR: 2.77-5.27), non-suppressed levels of TSH: $4.34 \mu \mathrm{U} / \mathrm{mL}$ (NR: 0.46-4.68) and thyroglobulin $13.1 \mathrm{ng} / \mathrm{mL}$ (3.5-77.0). TSH receptor antibodies were negative. She also performed a TRH test which revealed an exaggerated response of TSH (Fig. 2). Thyroid ultrasonography showed nodules in the left and right lobes with diameter ranging from 9 to $24 \mathrm{~mm}$.

The RTH syndrome was also investigated in the mother and the only sister (the patient had no children) and no clinical and laboratory alterations were detected, thus indicating a de novo origin of the syndrome.

\section{Outcome and follow up}

The patient received a diagnosis of generalized RTH syndrome with a rare mutation of the $T R B$ gene. She underwent thyroid surgery at two different times and the histological diagnosis was a multinodular goiter.

She did not take any drugs other than L-T4 for thyroid disorder and hormone therapy for breast cancer. At the last medical examination, L-T4 therapy was increased up to $100 \mu \mathrm{g}$ four times a week and $125 \mu \mathrm{g}$ three times a week. Her TH continues to be elevated with non-suppressed TSH levels (free T4: $2.38 \mathrm{ng} / \mathrm{dL}$, free T3: $6.65 \mathrm{pg} / \mathrm{mL}$ and TSH: $3.52 \mu \mathrm{U} / \mathrm{mL})$.

\section{Discussion}

RTH is a syndrome characterized by reduced responsiveness of target tissues to $\mathrm{TH}$, clinically described for the first time in 1967 (1). RTH $\beta$, due to TRB gene variants, was first identified in 1989 (5), while mutations in the TRA gene were discovered in 2012 (6). The classification of RTH syndromes also includes TH cell membrane transport defects due to mutations in the monocarboxylate transporter 8 (MTC8) gene (7) and metabolism defects

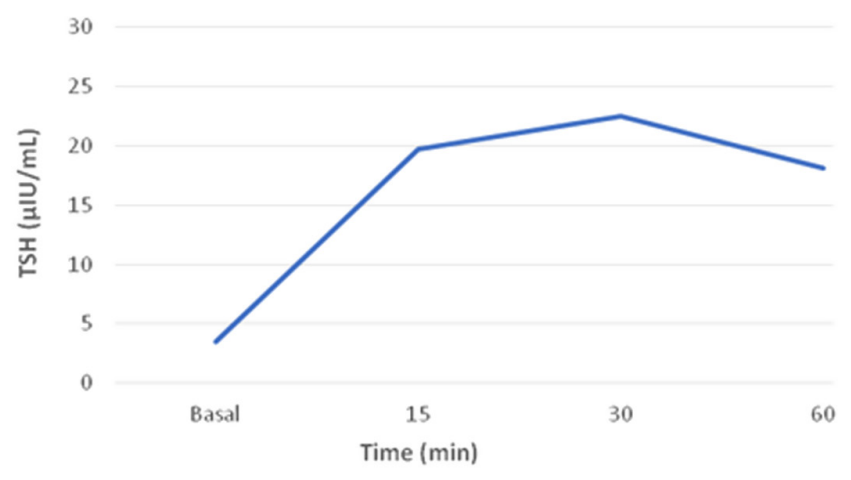

Figure 2

Exaggerated response of TSH to TRH test. due to mutations in the selenocysteine-binding protein 2 (SECISBP2) gene (8).

Diagnosis of RTH is usually based on the clinical finding of discrepant thyroid function tests and confirmed by a genetic test. The most frequent variants of the TRB gene, located on chromosome 3 , are single-nucleotide substitutions in exons 7 to 10 which cause the reduction of the TR affinity for T3 or an impaired interaction with the cofactors (coactivators and corepressors), in target tissues (4). Only $15 \%$ of patients with clinical features of RTH $\beta$ have no detectable mutations in the TRB gene and are classified as nonTR -RTH.

The biochemical hallmark of RTH $\beta$ is the persistent elevation of serum-free T4 and T3, normal or nonsuppressed serum TSH levels and increase of TSH levels after the TRH test. In our case, the patient showed an exaggerated response to $\mathrm{TSH}$. This response allowed to exclude the presence of a TSH-secreting pituitary adenoma characterized by the absence of TSH response to the TRH test. Laboratory tests also excluded the presence of resistance to exogenous thyroxine (RETH). Our patient had non-suppressed TSH levels with high FT3 and FT4 values. Compared to RTH $\beta$, patients with RETH usually have elevated TSH levels, normal FT3 values with significantly reduced $\mathrm{T} 3 / \mathrm{T} 4$ ratios suggesting the presence of FT4 defects of deiodination (9).

If this typical laboratory presentation is not recognized, RTH $\beta$ can be misdiagnosed leading to repeated and unnecessary treatments with antithyroid medications, radioiodine or thyroid surgery.

On the basis of clinical features, patients with RTH syndrome and TRB mutations may be classified in generalized resistance to TH (GRTH) and pituitary resistance to TH (PRTH). Patients with GRTH are usually euthyroid, while patients with PRTH have mild thyrotoxic manifestations in the peripheral tissues mainly expressing the THRA isoform (heart, bone and skeletal muscles). Nevertheless, this clinical distinction may be loose and more theoretical than actual. Indeed, TR $\beta$ variants found in both GRTH and PRTH may be the same and patients of the same family may present with either form.

Goiter is a common clinical manifestation. An increased biological activity of circulating TSH molecules may favor the formation of goiter in subjects with normal TSH levels. In RTH $\beta$ patients treated by surgical ablation, the goiter commonly relapses with nodular alterations and gross asymmetries, requiring additional surgery or radioiodine. In patients treated with total thyroidectomy for a missed diagnosis of RTH $\beta$, supraphysiological doses 
of L-T4 are necessary. In order not to cause thyrotoxicosis, the replacement treatment requires a careful monitoring, assessing not only the TSH as in conventional iatrogenic hypothyroidism but also the indices of peripheral thyroid hormone action.

In the present case, the patient showed an RTH $\beta$ syndrome with relapsing goiter treated with repeated surgical therapies and associated with a mutation in the $T R B$ gene. In our case, there was replacement of threonine (ACG) with methionine (ATG) at codon 310 and this mutation was described for the first time in an Italian patient. The same mutation was previously reported in a 38-year-old Korean patient with RTH and thyroid cancer (10). In addition, our patient received a diagnosis of breast ductal carcinoma.

The overall risk of malignancy in RTH $\beta$ patients is unknown. In the literature, there are few cases reporting the coexistence of RTH $\beta$ and thyroid carcinoma while no data are available on other malignancy.

Different studies reported abnormal expression or somatic mutations in the TRB and TRA gene in several human tumors as thyroid cancer, hepatocarcinoma, renal clear cell carcinoma and breast cancer $(11,12)$.

The knock-in mouse model harboring the Trb PV variant $\left(\operatorname{Tr} b^{P V / P V}\right)$, which recapitulates the dysregulation of the hypothalamus-pituitary-thyroid axis of human RTH, spontaneously develops follicular thyroid cancer (13). Interestingly, in this model, thyroid carcinoma occurs either when both THRB alleles are mutated or when one allele is mutated and other allele is deleted. In another study, mammary hyperplasia was reported in $36 \%$ of the $T r b^{P V / P V}$ mice and when heterozygous or homozygous PV variants were introduced in mice susceptible to mammary cancers $\left(\right.$ Pten $\left.^{+-}\right)$, their risk of malignancies was markedly increased(14).

Nevertheless, the RTH $\beta$ patients harbor heterozygous variants in the TRB gene and their susceptibility to cancers might not be increased compared with the general population. Indeed, also in the animal models, a single $\operatorname{Tr}^{P V}$ allele is neither associated with follicular carcinoma nor with mammary gland abnormalities.

In conclusion, here we report a case of RTH syndrome with a rare mutation of the TRB gene. RTH is a rare condition that must be considered for the management of patients with goiter, the elevation of $\mathrm{TH}$ and non-suppressed serum TSH levels in order to avoid unnecessary treatments. Further studies are needed to investigate the association between tumorigenesis and RTH.

\section{Declaration of interest}

Luca Persani is a Senior Editor of Endocrinology, Diabetes and Metabolism Case Reports. Luca Persani was not involved in the review or editorial process for this paper, on which he is listed as an author.

\section{Funding}

The research was partially supported by Funds of Ricerca Corrente of Istituto Auxologico Italiano (acronym: RTH2018)

\section{Patient consent}

Written informed consent has been obtained from the patient for publication of this report.

\section{Author contribution statement}

M D P collected the data and drafted the case report. F M, is the physician responsible for the patient, proposed and supervised the case report, collected the data and edited the manuscript. I C and L P performed the genetic test and prepared the relative image shown in the manuscript. All authors contributed to the case report editing, read and approved the final manuscript.

\section{References}

1 Refetoff S, DeWind LT \& DeGroot LJ. Familial syndrome combining deaf-mutism, stuppled epiphyses, goiter and abnormally high PBI: possible target organ refractoriness to thyroid hormone. Journal of Clinical Endocrinology and Metabolism 196727 279-294. (https://doi. org/10.1210/jcem-27-2-279)

2 Refetoff S, Bassett JH, Beck-Peccoz P, Bernal J, Brent G, Chatterjee K, De Groot LJ, Dumitrescu AM, Jameson JL, Kopp PA, et al. Classification and proposed nomenclature for inherited defects of thyroid hormone action, cell transport, and metabolism. European Thyroid Journal 20143 7-9. (https://doi.org/10.1159/000358180)

3 Dumitrescu AM \& Refetoff S. The syndromes of reduced sensitivity to thyroid hormone. Biochimica et Biophysica Acta 20131830 3987-4003. (https://doi.org/10.1016/j.bbagen.2012.08.005)

4 Persani L \& Campi I. Syndromes of resistance to thyroid hormone action. Experientia Supplementum 2019111 55-84.

5 Sakurai A, Takeda K, Ain K, Ceccarelli P, Nakai A, Seino S, Bell GI, Refetoff S \& DeGroot LJ. Generalized resistance to thyroid hormone associated with a mutation in the ligand-binding domain of the human thyroid hormone receptor beta. PNAS 198986 8977-8981. (https://doi.org/10.1073/pnas.86.22.8977)

6 Bochukova E, Schoenmakers N, Agostini M, Schoenmakers E, Rajanayagam O, Keogh JM, Henning E, Reinemund J, Gevers E, Sarri $\mathrm{M}$, et al. A mutation in the thyroid hormone receptor alpha gene. New England Journal of Medicine 2012366 243-249. (https:// doi.org/10.1056/NEJMoa1110296)

7 Friesema EC, Grueters A, Biebermann H, Krude H, von Moers A, Reeser M, Barrett TG, Mancilla EE, Svensson J, Kester MH, et al. Association between mutations in a thyroid hormone transporter and severe X-linked psychomotor retardation. Lancet 2004364 1435-1437. (doi:10.1016/S0140-6736(04)17226-7)

8 Dumitrescu AM, Liao XH, Abdullah MS, Lado-Abeal J, Majed FA, Moeller LC, Boran G, Schomburg L, Weiss RE \& Refetoff S. Mutations in SECISBP2 result in abnormal thyroid hormone metabolism. Nature Genetics 200537 1247-1252. (https://doi.org/10.1038/ng1654) 
9 Lacamara N, Lecumberri B, Barquiel B, Escribano A, GonzalezCasado I, Alvarez-Escola C, Aleixandre-Blanquer F, Morales F, Alfayate R, Bernal-Soriano MC, et al. Identification of resistance to exogenous thyroxine in humans. Thyroid 202030 1732-1744. (https://doi.org/10.1089/thy.2019.0825)

10 Kim HK, Kim D, Yoo EH, Lee JI, Jang HW, Tan AH, Hur KY, Kim JH Kim KW, Chung JH, et al. A case of resistance to thyroid hormone with thyroid cancer. Journal of Korean Medical Science 201025 1368-1371. (https://doi.org/10.3346/jkms.2010.25.9.1368)

11 Kim WG \& Cheng SY. Thyroid hormone receptors and cancer. Biochimica et Biophysica Acta 20131830 3928-3936. (https://doi. org/10.1016/j.bbagen.2012.04.002)
12 Liu YC, Yeh CT \& Lin KH. Molecular functions of thyroid hormone signaling in regulation of cancer progression and anti-apoptosis. International Journal of Molecular Sciences 2019204986 (https://doi. org/10.3390/ijms20204986)

13 Suzuki H, Willingham MC \& Cheng SY. Mice with a mutation in the thyroid hormone receptor beta gene spontaneously develop thyroid carcinoma: a mouse model of thyroid carcinogenesis. Thyroid 2002 12 963-969. (https://doi.org/10.1089/105072502320908295)

14 Guigon CJ, Kim DW, Willingham MC \& Cheng SY. Mutation of thyroid hormone receptor-beta in mice predisposes to the development of mammary tumors. Oncogene $2011303381-3390$. (https://doi.org/10.1038/onc.2011.50)

Received in final form 6 April 2021

Accepted 13 April 2021 